\title{
Влияние кислорода при осаждении тонкой пленки оксида индия-олова методом магнетронного распыления для гетеропереходных солнечных элементов
}

\author{
(С) А.Ф. Иванов ${ }^{1,2}$, Ф.С. Егоров ${ }^{1}$, Н.Д. Платонов ${ }^{2}$, В.Л. Матухин ${ }^{2}$, Е.И. Теруков ${ }^{3,4}$ \\ ${ }^{1} \mathrm{OOO} \mathrm{„Хевел“,}$ \\ 429965 Новочебоксарск, Россия \\ ${ }^{2}$ Казанский государственный энергетический университет, \\ 420066 Казань, Россия \\ ${ }^{3}$ Физико-технический институт им. А.Ф. Иоффе Российской академии наук, \\ 194021 Санкт-Петербург, Россия \\ ${ }^{4}$ Санкт-Петербургский государственный электротехнический университет „ЛЭТИ“ им. В.И. Ульянова (Ленина), \\ 197376 Санкт-Петербург, Россия \\ E-mail: ivanovaleksandrf@yandex.ru; f.egorov@hevelsolar.com
}

Поступила в Редакцию 27 сентября 2021 г.

В окончательной редакции 1 октября 2021 г.

Принята к публикации 1 октября 2021 г.

\begin{abstract}
Проведено экспериментальное исследование оптоэлектронных свойств тонких пленок оксида индия и олова в зависимости от содержания кислорода в общем потоке газов при напылении данных пленок методом магнетронного распыления мишени на постоянном токе. Была исследована зависимость выходных параметров гетеропереходных тонкопленочных солнечных элементов в зависимости от парциального давления кислорода в вакуумной камере при осаждении слоя оксида индия и олова. Максимальное значение эффективности фотоэлектрического преобразования солнечного элемента достигнуто при парциальном давлении кислорода в вакуумной камере $\sim 6.5$ Торр.
\end{abstract}

Ключевые слова: гетеропереходный тонкопленочный солнечный элемент, оксид индия и олова, магнетронное распыление.

DOI: 10.21883/FTP.2022.03.52117.9747

\section{1. Введение}

Прозрачные проводящие оксиды (ППО) необходимы в качестве прозрачных электродов в технологиях производства современных фотоэлектрических преобразователей (ФЭП). Благодаря своим оптоэлектронным свойствам часто используемыми ППО в этой области являются тонкие прозрачные пленки оксида индия-олова ITO (Inlium Tin Oxide) [1]. Гетеропереходные тонкопленочные солнечные элементы СЭ - HIT (Heterojunction with Intrinsic Thin-layer solar cells) на основе тонкопленочного аморфного кремния $a-\mathrm{Si}: \mathrm{H}$ уже продемонстрировали свои высокие фотоэлектрические характеристики и признаны в настоящее время как одни из наиболее перспективных ФЭП. Суть технологии их производства заключается в формировании гетеропереходов на поверхности монокристаллических кремниевых $c$-Si пластин путем нанесения тонких пленок аморфного кремния $a-\mathrm{Si}: \mathrm{H}$ различного типа [2-4]. НІТ-элементы имеют высокое напряжение холостого хода $\left(V_{\mathrm{OC}}\right)$, как правило, значительно выше $730 \mathrm{MB}$, мировой рекорд коэффициента заполнения вольт-амперных характеристик (fill factor) $(F F=84.9 \%)$ и значения эффективности фотоэлектрического преобразования $(\eta=26.7 \%)$ продемонстрировала компания Kaneka Corp в 2017 году [5]. Кроме того, тонкие пленки $a$-Si:H осаждаются при температуре $\sim 200^{\circ} \mathrm{C}$, что значительно снижает тепловой баланс при производстве солнечных элементов и в то же время позволяет использовать техническое оборудование с высокой производительностью [2-5]. В архитектуре НІТ-элементов на фронтальную и тыльную стороны солнечного элемента требуется осаждение слоя ППО для обеспечения эффективного пропускания света в кремниевое устройство и сохранения высокой удельной электропроводности [6-9].

Несмотря на высокую эффективность НІТ-элементов, некоторые вопросы, связанные с оптимизацией процесса получения каждого отдельного слоя структуры ячейки, остаются открытыми. Они включают в себя ряд технических вопросов, связанных с оптимизацией процесса осаждения ППО, так как этот этап может определенно изменить интерфейсные свойства структуры устройства и повлиять на выходные параметры готового СЭ. Среди процессов осаждения ППО наиболее распространенным методом является магнетронное распыление [10-12]. Сообщалось, что оптоэлектронные свойства тонких пленок ITO зависят в основном от параметров роста, включая поток кислорода [13-15]. В некоторых исследованиях показано, что увеличение потока кислорода во время осаждения снижает концентрацию основных носителей заряда и влияет на ширину запрещенной зоны тонких пленок ITO [13,14]. C.G. Choi с соавт. [15] обнаружили, что пропускание пленки ITO в видимом диапазоне не коррелировало с потоком кислорода, в то время как 
Y.J. Kim с соавт. [10] установили, что как холловская подвижность основных носителей заряда, так и оптическое пропускание пленки увеличиваются по отношению к потоку кислорода. Определенные различия в полученных результатах требуют проведения дополнительных исследований.

Цель данной работы заключалась в изучении влияния кислорода, содержащегося в общем потоке газов во время процесса магнетронного напыления, на оптические и электрофизические свойства тонких пленк ITO. Кроме того, исследовалось влияние содержания кислорода в вакуумной камере при магнетронном напылении тонких пленок ITO на выходные параметры готовых НІТ-элементов.

\section{2. Методика эксперимента}

Образцы для исследования влияния кислорода, содержащегося в общем потоке газов, на оптические и электрофизические свойства тонких пленок ITO получали методом магнетронного распыления мишени $\left(\mathrm{In}_{2} \mathrm{O}_{3}=95 \%\right.$ и $\left.\mathrm{SnO}_{2}=5 \%\right)$ на постоянном токе. Напыление проводилось при температуре $200^{\circ} \mathrm{C}$ и давлении в вакуумной камере не более $6 \cdot 10^{-3}$ мбар при различных отношениях кислорода к общему потоку газов:

$$
r\left(\mathrm{O}_{2}\right)=\mathrm{O}_{2} /\left(\mathrm{Ar}+\mathrm{O}_{2}\right)
$$

где $\mathrm{O}_{2}$ - поток кислорода во время процесса магнетронного напыления тонкой пленки ITO, Ar - поток аргона во время процесса магнетронного напыления тонкой пленки ITO. Плотность мощности постоянного тока составляла $1.13 \mathrm{BT} / \mathrm{cm}^{2}$, a $r\left(\mathrm{O}_{2}\right)=2.2 \cdot 10.4 \%$. Толщину пленок $(T h k)$ измеряли эллипсометрическим методом на спектроскопическом эллипсометре AccuMap-SE ${ }^{\mathrm{TM}}$ $\mathrm{V}-1500$. Удельное поверхностное сопротивление $(R)$ определяли четырехзондовым методом с помощью системы JANDEL RM3-ARC. Поверхностную концентрацию $(n)$ и холловскую подвижность $(\mu)$ основных носителей заряда определяли с помощью системы HMS-3000. Каждый из образцов измеряли по несколько раз: в 4-5 разных положениях (после каждого измерения на системе HMS-3000 образец поворачивали на 90). Суммарный результат измерений приводится как среднее значение 4-5 измерений. Оптическое пропускание $(t)$ и отражение $(r)$ пленок измерялись с помощью спектрометра Perkin Elmer Lambda 950 с интегрирующей сферой, а коэффициент поглощения $(a)$ определяли как $a=100 \%-t-r$.

Для исследования влияния содержания кислорода в вакуумной камере при магнетронном напылении тонких пленок ITO на выходные параметры НІТ-элементов были изготовлены СЭ из высококачественных пластин $c$-Si $n$-типа. Схема НIT-элемента изображена на рис. 1. Пластины предварительно подвергали пирамидальному текстурированию в щелочном растворе, химической очистке и погружали в плавиковую кислоту перед плазменнохимическим осаждением из паровой фазы собственных

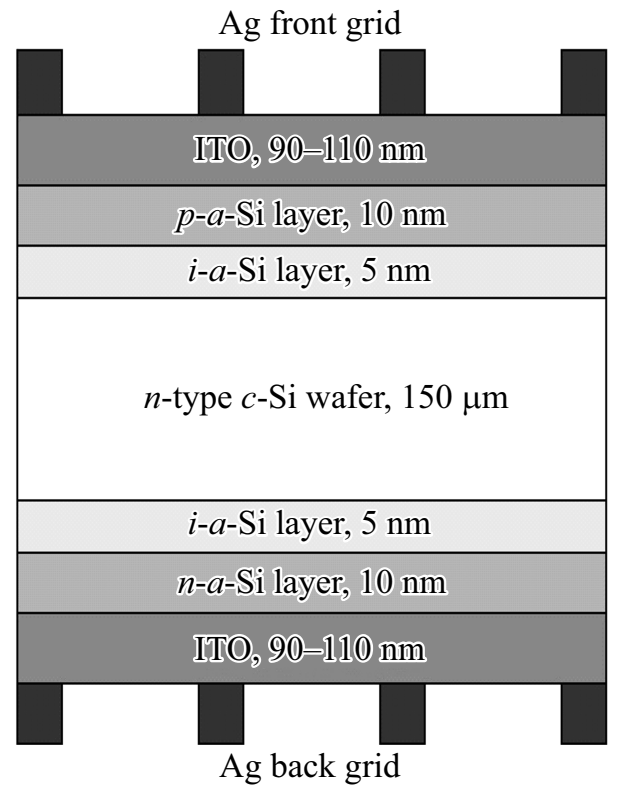

Рис. 1. Схематическое изображение НIT-элемента.

и легированных слоев $a$-Si:H. Пленки ITO использовались в качестве фронтального и тыльного электродов и напылялись методом магнетронного распыления мишени ITO $\left(\mathrm{In}_{2} \mathrm{O}_{3}=95 \%\right.$ и $\left.\mathrm{SnO}_{2}=5 \%\right)$ на постоянном токе при температуре $200^{\circ} \mathrm{C}$ и давлении в вакуумной камере не более $10^{-2}$ мбар. Поверхностная плотность мощности постоянного тока составляла $2.08 \mathrm{BT} / \mathrm{cm}^{2}$, а парциальное давление кислорода $\left(P_{\mathrm{O}_{2}}\right)$ в вакуумной камере варьировалось $P_{\mathrm{O}_{2}}=4.5 \cdot 10^{-7}-10^{-6}$ Торр. После напыления слоя ITO следовали серебряная контактная сетка, нанесенная методом трафаретной печати, и отжиг СЭ в течение 40 мин при температуре $200^{\circ} \mathrm{C}$.

Парциальное давление кислорода в вакуумной камере детектировалось с помощью системы HIDEN HPR-30 A2 с системой дифференциальной откачки и масс-спектрометром HAL0 201 RC. Исследования выходных параметров опытных образцов проводились с помощью импульсного имитатора солнечного излучения Pasan Spot ${ }^{\mathrm{LIGTH}}$ Highcap с системой контактирования $\mathrm{Grid}^{\mathrm{TOUCH}}$, разработанной компанией Pasan для измерения параметров солнечных ячеек, выполненных по безбасбарной технологии. Вольт-амперные характеристики (BAX) НІТ-элементов измерялись в условиях AM1.5G $\left(1000 \mathrm{BT} / \mathrm{M}^{2}\right)$.

\section{3. Экспериментальные результаты}

Результаты измерения электрофизических характеристик образцов ITO представлены в таблице. По полученным данным были построены зависимости от отношения кислорода к общему потоку газов $r\left(\mathrm{O}_{2}\right)$ поверхностной концентрации, холловской подвижности основных носи- 


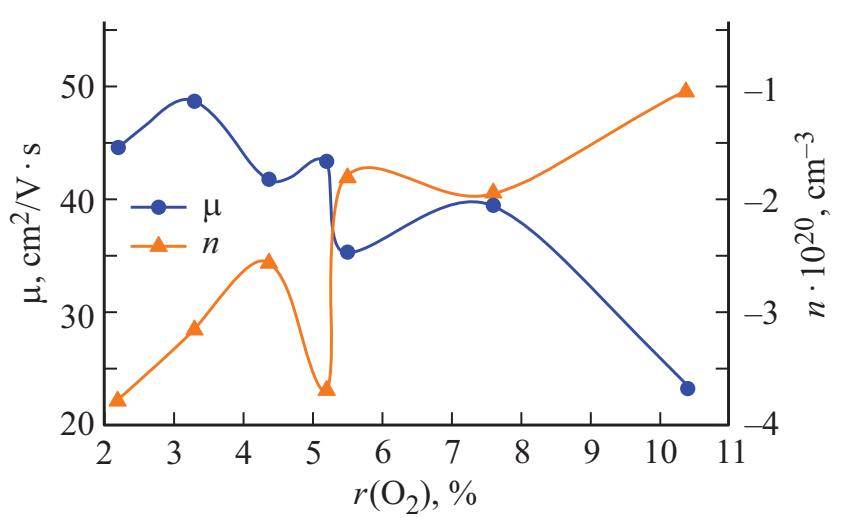

Рис. 2. Зависимость холловской подвижности $(\mu)$ и поверхностной концентрации $(n)$ основных носителей заряда от содержания кислорода в общем потоке газов $r\left(\mathrm{O}_{2}\right)$ при напылении тонких пленок ITO.

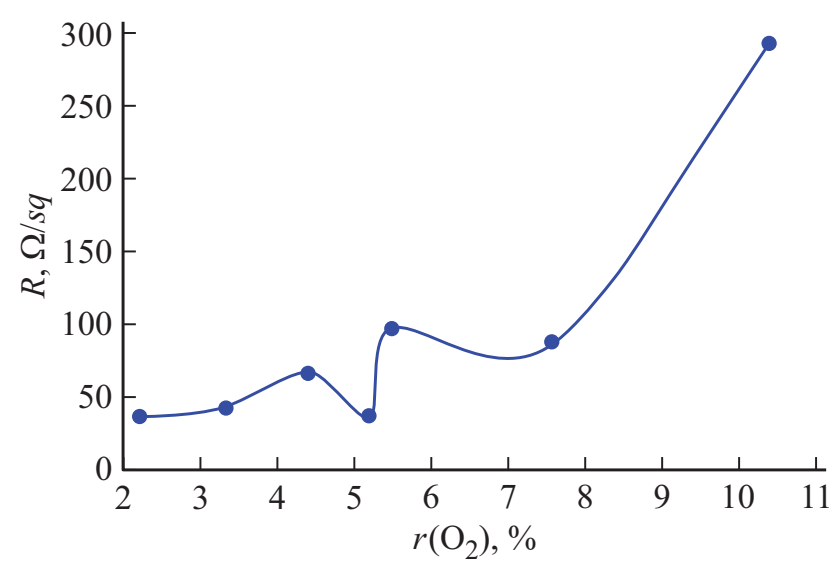

Рис. 3. Зависимость поверхностного сопротивления пленки ITO $(R)$ от содержания кислорода в общем потоке газов $r\left(\mathrm{O}_{2}\right)$ при напылении тонких пленок ITO.
Результаты измерения электрофизических характеристик образцов ITO

\begin{tabular}{c|r|c|c|c}
\hline$r\left(\mathrm{O}_{2}\right), \%$ & $T h k$, нм & $R$, Ом/квадрат & $\mu, \mathrm{cm}^{2} / \mathrm{B} \cdot \mathrm{c}$ & $n \cdot 10^{20}, \mathrm{~cm}^{-3}$ \\
\hline 2.2 & 105.73 & 34.94 & 44.63 & -3.777 \\
3.3 & 97.29 & 41.96 & 48.73 & -3.147 \\
4.4 & 88.67 & 65.59 & 41.74 & -2.562 \\
5.2 & 106.73 & 36.57 & 43.33 & -3.681 \\
5.5 & 103.31 & 95.66 & 35.29 & -1.795 \\
7.6 & 94.41 & 86.9 & 39.42 & -1.939 \\
10.4 & 90.28 & 292.4 & 23.29 & -1.019
\end{tabular}

телей заряда и удельного поверхностного сопротивления исследуемых образцов ITO (рис. 2-4).

Измерение поверхностной концентрации и холловской подвижности основных носителей заряда пленок ITO проводилось с помощью четырехзондового метода Ван-дер-Пау. При этом электроды контактировали с углами исследуемой ITO-пленки, которая имела форму квадрата с размерами $1 \times 1$ см. Таким образом, электрические свойства слоев ITO были измерены относительно параметра $r\left(\mathrm{O}_{2}\right)$. Поверхностная концентрация основных носителей заряда изменялась от $n=-3.777 \cdot 10^{20}$ до $-1.019 \cdot 10^{20} \mathrm{~cm}^{-3}$ при изменении параметра $r\left(\mathrm{O}_{2}\right)$ от 2.2 до $10.4 \%$ (рис. 2). Для всего исследуемого диапазона $r\left(\mathrm{O}_{2}\right)$ холловская подвижность основных носителей заряда изменялась от $\mu=44.63$ до $23.29 \mathrm{~cm}^{2} / \mathrm{B} \cdot \mathrm{c}$ (рис. 2). Удельное поверхностное сопротивление увеличивалось в диапазоне $R=34.94-292.4$ Ом/квадрат, при изменении $r\left(\mathrm{O}_{2}\right)=2.2-10.4 \%$ (рис. 3 ).

При низком значении поверхностной концентрации основных носителей заряда $(n)$ возможными ограни-

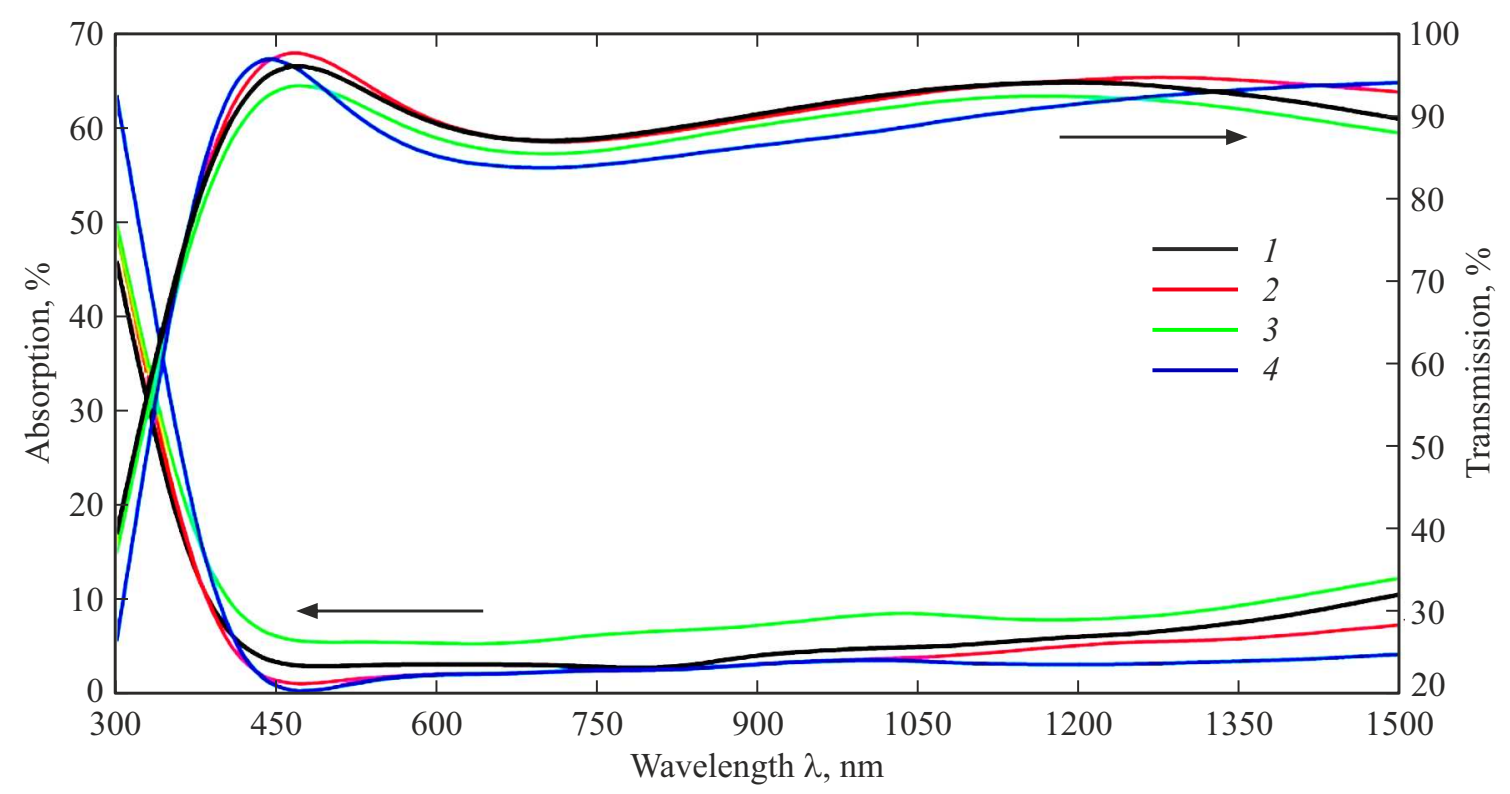

Рис. 4. Зависимость коэффициентов поглощения и пропускания пленки ITO от содержания кислорода в общем потоке газов при напылении тонких пленок ITO, $r\left(\mathrm{O}_{2}\right)$ в \%: $2.2(1), 3.3(2), 5.2(3), 10.4$ (4). (Цветной вариант рисунка представлен в электронной версии статьи). 


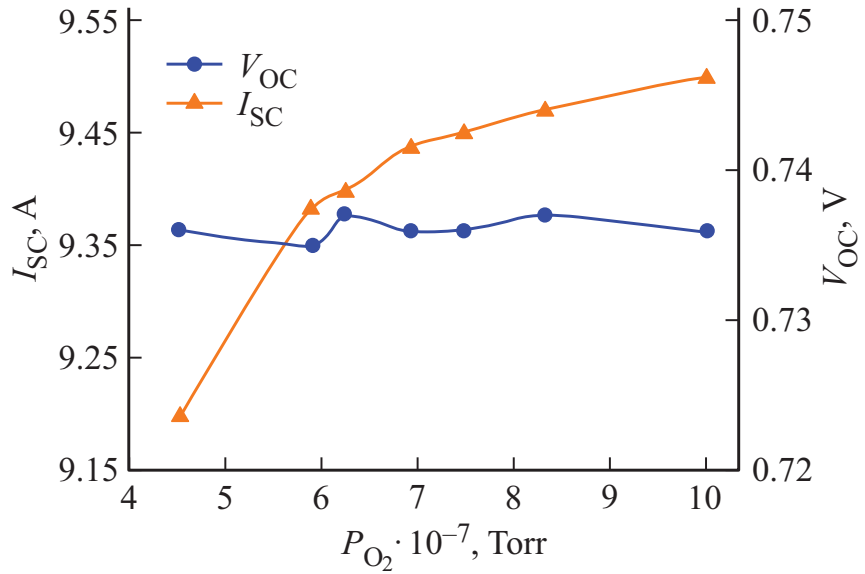

Рис. 5. Зависимости тока короткого замыкания $\left(I_{\mathrm{SC}}\right)$ и напряжения холостого хода $\left(V_{\mathrm{OC}}\right)$ НІТ-элемента от парциального давления кислорода в вакуумной камере при магнетронном напылении тонкой пленки ITO.

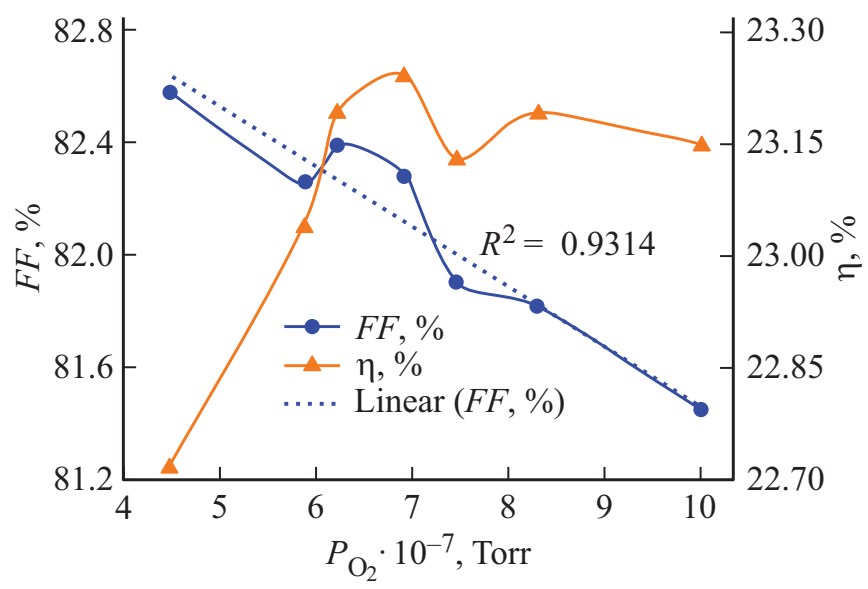

Рис. 6. Зависимости коэффициента заполнения $\mathrm{BAX}(F F)$ и эффективности фотоэлектрического преобразования $(\eta)$ HITэлемента от парциального давления кислорода в вакуумной камере при магнетронном напылении тонкой пленки ITO.

чивающими факторами для холловской подвижности основных носителей заряда $(\mu)$ являются рассеяние этих носителей на ионизованных примесях и рассеяния на фононах. Однако при большой концентрации электронов $n$ рассеяние на ионизованных примесях является основным ограничивающим фактором для подвижности $\mu[16,17]$. Подвижность основных носителей заряда принимает максимальное значение в случае, когда перенос носителей заряда в основном ограничивался электрон-фононным взаимодействием и потери на ионизованных примесях никак не влияли на величину $\mu$ [17].

На рис. 4 показаны графики зависимости коэффициентов пропускания и поглощения пленок ITO при различных значениях $r\left(\mathrm{O}_{2}\right)$. Образцы с $n=-3.777 \cdot 10^{20}$ и $-3.681 \cdot 10^{20} \mathrm{~cm}^{-3}$ обладали низким коэффициентом поглощения в видимом и ближнем инфракрасном (ИК) областях спектра. В ближнем ультрафиолетовом (УФ) диапазоне также может наблюдаться сдвиг БурштейнаMocca (т. е. сдвиг края поглощения с увеличением $n$ при уменьшении $\left.r\left(\mathrm{O}_{2}\right)\right)$.

Было обнаружено, что оптическое поглощение пленок в ближнем ИК-диапазоне сильно увеличивается при $r\left(\mathrm{O}_{2}\right)=2.2$ и 5.2\%, что может быть связано с увеличением $n$, измеренной с помощью эффекта Холла (рис. 1). Следует отметить, что тонкая пленка ITO, нанесенная при $r\left(\mathrm{O}_{2}\right)=5.2 \%$, показывает более высокое поглощение в видимом диапазоне по сравнению с остальными образцами.

Результаты исследования влияния содержания кислорода в вакуумной камере при магнетронном напылении тонких пленок ITO на выходные параметры НITэлементов представлены на рис. 5 и 6 . Независимо от парциального давления кислорода $\left(P_{\mathrm{O}_{2}}\right)$, при напылении слоя ITO, высокое значение $V_{\mathrm{OC}}$ систематически наблюдалось для всех НІТ-элементов, что указывает на эффективность применяемого процесса гидрогенизированной пассивации аморфных слоев. С увеличением $P_{\mathrm{O}_{2}}$ также увеличивались токи короткого замыкания $\left(I_{\mathrm{SC}}\right)$ и эффективности фотоэлектрического преобразования $(\eta)$ HITэлементов. Однако при $P_{\mathrm{O}_{2}}>6.22 \cdot 10^{-7}$ Торр линейный рост $I_{\mathrm{SC}}$ прекращался, что объясняется резистивными потерями в слое ITO. Так как с увеличением $P_{\mathrm{O}_{2}}, F F$ уменьшается линейно (линия тренда $F F$ ), а линейный рост $I_{\mathrm{SC}}$ останавливался при $P_{\mathrm{O}_{2}}>6.22 \cdot 10^{-7}$ Торр, то $\eta$ НІТ-элементов также прекращает увеличиваться.

\section{4. Заключение}

Результаты проведенного исследования показали влияние кислорода, содержащегося в общем потоке газов, на оптические и электрофизические свойства тонких пленок ITO, а также влияние парциального давления кислорода в вакуумной камере при магнетронном напылении тонкой пленки ITO на выходные параметры НITэлементов. Все пленки ITO с $r\left(\mathrm{O}_{2}\right)>5.2 \%$ показали низкое поглощение в видимом и ближнем ИК-областях спектра, а оптическое поглощение пленок в ближнем ИК-диапазоне сильно увеличивалось с уменьшением содержания кислорода, что могло быть связано с увеличением поверхностной концентрации основных носителей заряда, что в свою очередь подтверждается измерением эффекта Холла. Минимальное значение удельного поверхностного сопротивления и поверхностной концентрации основных носителей заряда были достигнуты при самом низком значении параметра $r\left(\mathrm{O}_{2}\right)$. С увеличением содержания кислорода в общем потоке газов при напылении тонких пленок ITO холловская подвижность основных носителей заряда уменьшалась, и минимальная подвижность основных носителей заряда, достигнутая для пленок ITO, составила $23 \mathrm{~cm}^{2} / \mathrm{B} \cdot \mathrm{c}$. Кроме того, было обнаружено, что при использовании ITO в качестве фронтального и тыльного контактов в НІТ-элементах высокое значение эффективности фотоэлектрического 
преобразования достигнуто при парциальном давлении кислорода в вакуумной камере $~ 6.5$ Торр, что можно объяснить оптимальными оптическими и электрофизическими параметрами пленки ITO. Возможность осаждения при низких температурах и отличные оптические и электрофизические свойства пленки ITO подтверждают, что ITO является одним из лучших кандидатов в качестве прозрачного проводящего электрода не только для солнечных элементов, но и для многих чувствительных к температуре устройств, таких как органические светодиоды и солнечные элементы на основе перовскита.

\section{Конфликт интересов}

Авторы заявляют об отсутствии конфликта интересов.

\section{Список литературы}

[1] B.G. Lewis, D.C. Paine. MRS Bull., 25 (8), 22 (2000).

[2] S.Q. Xiao, S. Xu, H.P. Zhou, D.Y. Wei, S.Y. Huang, L.X. Xu, C.C. Sern, Y.N. Guo, S. Khan. Appl. Phys. Lett., 100 (23), 233902 (2012).

[3] J. Haschke, O. Dupré, M. Boccard, C. Ballif. Sol. Energy Mater. Sol. Cells, 187, 140 (2018).

[4] Е.И. Теруков, А.С. Абрамов, Д.А. Андронников, К.В. Емцев, И.Е. Панайотти, А.С. Титов, Г.Г. Шелопин. ФТП, 52 (7), 792 (2018).

[5] K. Yoshikawa, H. Kawasaki, W. Yoshida, T. Irie, K. Konishi, K. Nakano, T. Uto, D. Adachi, M. Kanematsu, H. Uzu, K. Yamamoto. Nature Energy, 2 (5), 17032 (2017).

[6] Z.C. Holman, M. Filipič, A. Descoeudres, S. De Wolf, F. Smole, M. Topič, C. Ballif. J. Appl. Phys., 113, 013107 (2013).

[7] L. Korte, E. Conrad, H. Angermann, R. Stangl, M. Schmidt. Sol. Energy Mater. Sol. Cells, 93 (6), 905 (2009).

[8] K. Ji, J. Choi, H. Yang, H. Lee, D. Kim. Sol. Energy Mater. Sol. Cells, 95 (1), 203 (2011).

[9] Y.J. Kim, S.B. Jin, S.I. Kim, Y.S. Choi, I.S. Choi, J.G. Han. Thin Sol. Films, 518 (22), 6241 (2010).

[10] B. Zhang, X. Dong, X. Xu, P. Zhao, J. Wu. Sol. Energy Mater. Sol. Cells, 92 (10), 1224 (2008).

[11] A. Thøgersen, M. Rein, E. Monakhov, J. Mayandi, S. Diplas. J. Appl. Phys., 109 (11), 113532 (2011).

[12] S. Li, X. Qiao, J. Chen. Mater. Chem. Phys., 98 (1), 144 (2006).

[13] M.-C. Chen, S.-A. Chen. Thin Sol. Films, 517 (8), 2708 (2009).

[14] C.G. Choi, K. No, W.-J. Lee, H.-G. Kim, S.O. Jung, W.J. Lee, W.S. Kim, S.J. Kim, C. Yoon. Thin Sol. Films, 258 (2), 274 (1995).

[15] H. Hosono. J. Non-Cryst. Solids, 352, 851 (2006).

[16] R. Martins, P. Almeida, P. Barquinha, L. Pereira, A. Pimentel, I. Ferreira, E. Fortunato. J. Non-Cryst. Sol., 352, 1471 (2006).

[17] A.J. Leenheer, A.J. Leenheer, J.D. Perkins, M.F.A.M. van Hest, J.J. Berry, R.P. O'Hayre, D.S. Ginley. Phys. Rev. B, 7, 115215 (2008).

Редактор А.Н. Смирнов

\section{Influence of the oxygen during the deposition of an indium tin oxide thin film by magnetron sputtering for heterojunction solar cells}

\author{
A.F. Ivanov ${ }^{\mathbf{1}, 2}$, F.S. Egorov ${ }^{2}$, N.D. Platonov ${ }^{2}$, \\ V.L. Matukhin ${ }^{2}$, E.I. Terukov ${ }^{3,4}$ \\ ${ }^{1}$ Hevel LLC, \\ 429965 Novocheboksarsk, Russia \\ ${ }^{2}$ Kazan State Power Engineering University, \\ 420066 Kazan, Russia \\ ${ }^{3}$ loffe Institute, \\ 194021 St. Petersburg, Russia \\ ${ }^{4}$ St. Petersburg State Electrotechnical University „LETl“ \\ named after Ulyanov (Lenin), \\ 197376 St. Petersburg, Russia
}

\begin{abstract}
An experimental study of the optoelectronic properties of thin films of indium and tin oxide, depending on the oxygen content in the total gas flow during the deposition of these films, by the method of magnetron sputtering of a target at a direct current, has been carried out. The dependence of the output parameters of heterojunction thin-film solar cells depending on the partial pressure of oxygen in the vacuum chamber during the deposition of a layer of indium and tin oxide was investigated. The maximum value of the efficiency of photoelectric conversion of a solar cell was achieved at a partial pressure of oxygen in the vacuum chamber $\sim 6.5$ Torr.
\end{abstract}

